\title{
Healthcare Encounters Reference Identifier
}

National Cancer Institute

\section{Source}

National Cancer Institute. Healthcare Encounters Reference Identifier. NCI Thesaurus.

Code C123995.

A sequence of characters used to identify, name, or characterize the healthcare encounters reference. 